Reinnervation of a free muscle graft by nerves from an adjacent intact muscle is called muscular neurotization. This paper investigates the mechanisms and stimuli responsible for muscular neurotization in the rat. Sternohyoid or sternomastoid muscles were transplanted as free muscle grafts to the ventral surface of an intact sternohyoid muscle (feeder muscle). After several weeks the graft and underlying feeder muscle were removed together, frozen, serially sectioned, stained, and carefully examined for the presence or absence of nerves. It was concluded from a series of experiments that in this model muscular neurotization is a form of nerve regeneration. In order for muscular neurotization to occur, it is necessary to have (1) injury to the nerves of the intact feeder muscle and (2) a pathway upon which the regenerating nerves may grow into the graft.

MUSCLE \& NERVE $\quad 10: 530-536 \quad 1987$

\title{
EXPERIMENTAL INVESTIGATION OF MUSCULAR NEUROTIZATION IN THE RAT
}

\author{
RACHEL MUST, PhD
}

This paper contains the results of a series of experiments designed to examine the stimulus and mechanisms responsible for the form of nerve growth known as muscular neurotization. Muscular neurotization, a term that dates from clinical research done in the early part of this century,' describes the reinnervation of a free skeletal muscle graft by nerves from an adjacent intact muscle.

Several clinicians and investigators have confirmed that free skeletal muscle transplants will survive and become functional in a variety of laboratory animal models and in humans. ${ }^{2,3.5,6.8,9,11,12}$ The presence of nerves in these grafts has been confirmed by physiological testing for functional recovery of the grafts and by histological staining procedures. Although there is no doubt that nerves are present in mature free muscle grafts, the exact mechanisms and pathways of reinnervation have never been examined.

The first experiment defines a model for muscular neurotization using the rat neck strap mus-

From the Department of Anatomy and Cell Biology, University of Michigan Ann Arbor, MI

Acknowledgment: Supported by grants from NIH to Bruce M. Carlson No. P01 DE 07687

Address reprint requests to Dr. Must at the Department of Anatomy and Cell Brology. University of Michigan, Ann Arbor, Mi 48109.

Received for publication June 12,1985; revised manuscript accepted for publication September 11, 1986.

$0148 \cdot 639 \times / 1006 / 0530 \$ 04.00 / 7$

1987 John Wiley \& Sons, Inc cles. The goal of this experiment was to establish the existence of muscular neurotization as a phenomenon in the rat model. The second experiment was an examination of the role of the motor endplate region in muscular neurotization. The final four experiments attempted to define the roles of both nerve damage and the availability of nerve pathways in the process of muscular neurotization.

\section{MATERIALS AND METHODS}

These experiments used two of the long strap muscles of the neck, the sternohyoid and sternomastoid muscles (Fig. 1). Staining with acetylcholinesterase shows that the motor endplate region of the sternomastoid muscle is localized to a band that crosses the muscle near the point of nerve entry in the upper region of the middle third of the muscle. Staining of the sternohyoid muscle shows that the region of motor endplates is confined to a single band that arches slightly across the width of the midportion of the muscle.

Basic Operation. Male Sprague Dawley rats (Charles River, Portage, MI) (150-250 g) were anesthetized with ether or Metofane. The strap muscles of the neck were exposed through an incision in the ventral neck region and division of the salivary glands covering the muscles. The right sternohyoid or right sternomastoid muscles were excised from their origins and insertions, and all vascular and nervous connections were cut. The free muscle grafts were then placed onto the ventral side of the left ster- 


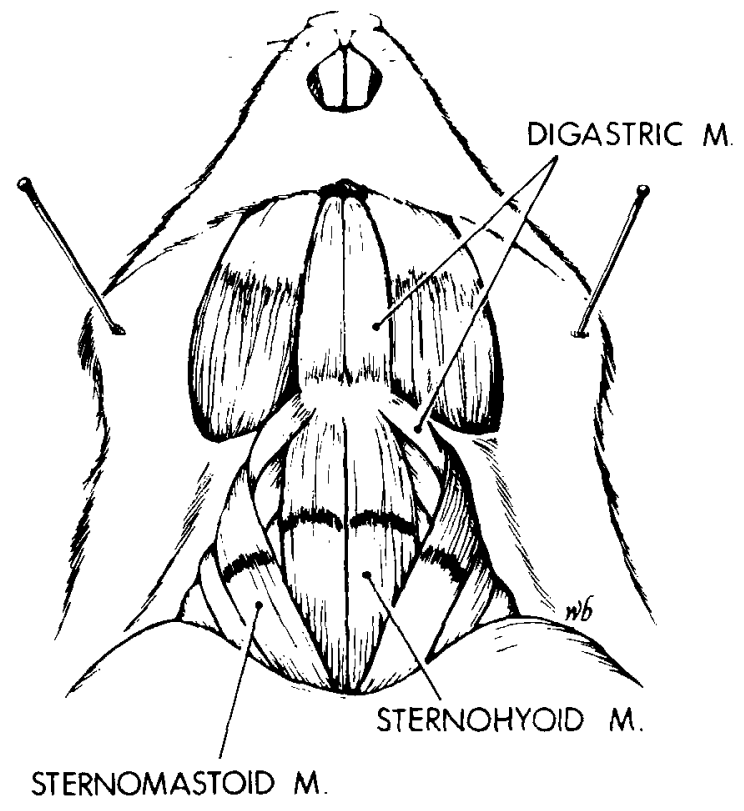

FIGURE 1. Strap muscies of the rat neck.

nohyoid muscle and sutured at each of their four corners with Ethicon 7-0 suture (Somerville, NJ). The intact sternohyoid muscle on which the graft was placed is referred to as the feeder muscle. The salivary glands were sutured together over the graft. The epidermis was then closed.
Histology. Both graft and underlying feeder muscle were removed together and placed on wooden tongue depressors, embedded in OCT embedding compound (Miles Scientific, Naperville, IL) and frozen in isopentane cooled with dry ice. Serial cryostat sections were placed on slides dipped in $3 \%$ EDTA at pH 7.2 to prevent contraction of muscle fibers. The slides were stained with the

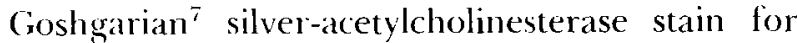
nerves and motor endplates (Fig. 2). Eosin was used as a back stain to visualize the cellular components of the muscle fibers and blood vessels.

\section{EXPERIMENTAL PROCEDURES AND RESULTS}

Experiment 1: Standard Grafts. The first experiment was designed to test the hypothesis that a free skeletal muscle graft becomes reinnervated when placed on top of an intact skeletal muscle.

Procedure and Results. In 24 animals the dorsal side of the right sternohyoid was sutured onto the ventral surface of the intact left sternohyoid muscle.

The regenerated grafts (7-65 days) varied in appearance upon gross examination. Some of the grafts had a well developed muscular body that covered almost the entire feeder muscle. Other grafts were much smaller, as if the graft had contracted and/or atrophied. Most of the grafts were very tightly attached to the feeder muscle by connective tissue.

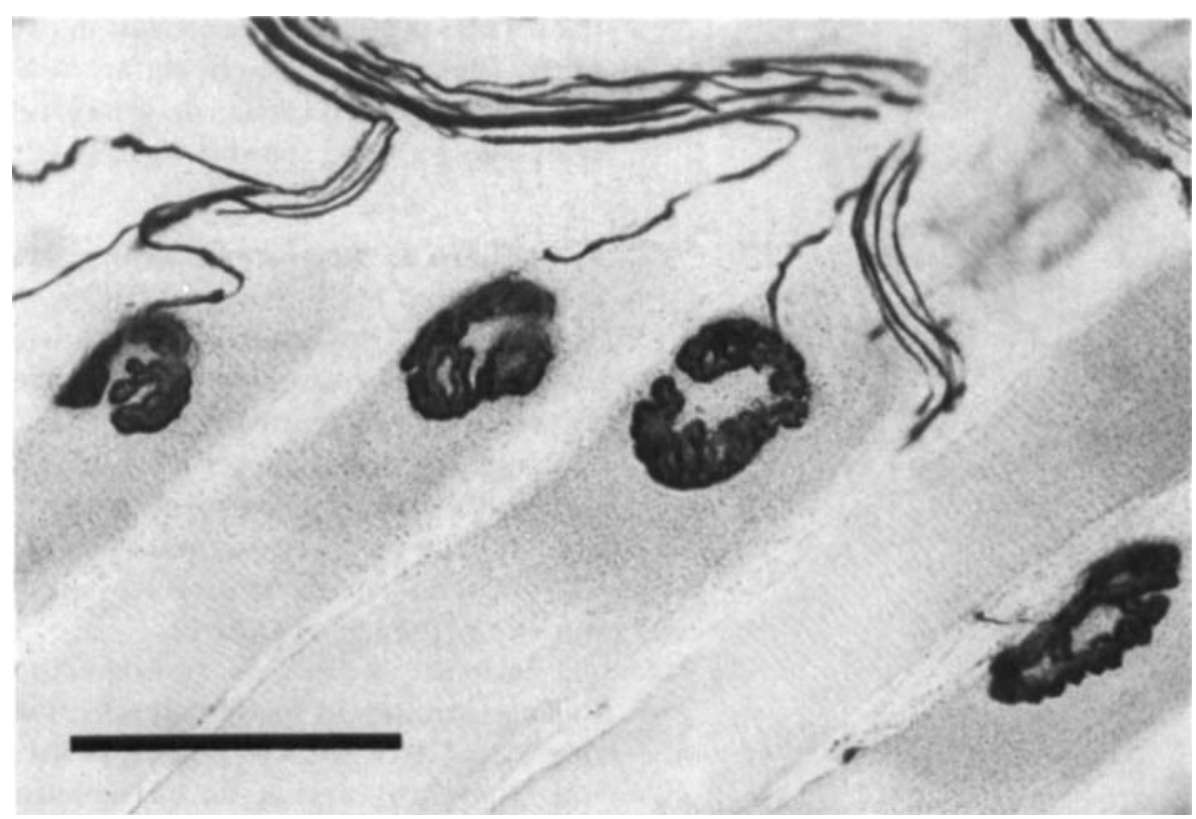

FIGURE 2. Nerves and motor endplates of rat skeletal muscle stained with Goshgarian silver-acetylcholinesterase procedure. Bar $=$ $100 \mu \mathrm{m}$. 
Examination of serial sections of $24 \mathrm{graft} /$ feeder muscle complexes (7-65 days) showed that 17 had nerves within the regenerated graft whereas 7 did not. Nerves were consistently seen in the grafts by 28 days. In several grafts the nerves could be traced as they crossed from the feeder muscle into the graft. As indicated by the cholinesterase stain, entering nerves were often associated with the old motor endplate region of the graft. The grafts were composed of regenerated muscle fibers typical of a free muscle graft."

Figure 3 shows a reconstruction made from amera lucida drawings taken from serial sections of the graft/feeder complex. The tracings from 8 adjacent $26 \mu \mathrm{m}$ sections were collated and retraced to give the image in Fig. 3. Black silver-stained nerves in the feeder muscle cross the connective tissue interface and enter the motor endplate region of the adjacent graft. Nerves appear to contact endplates within the grafts. It is not known, however, whether thesc are original endplates or newly formed esterase spots.

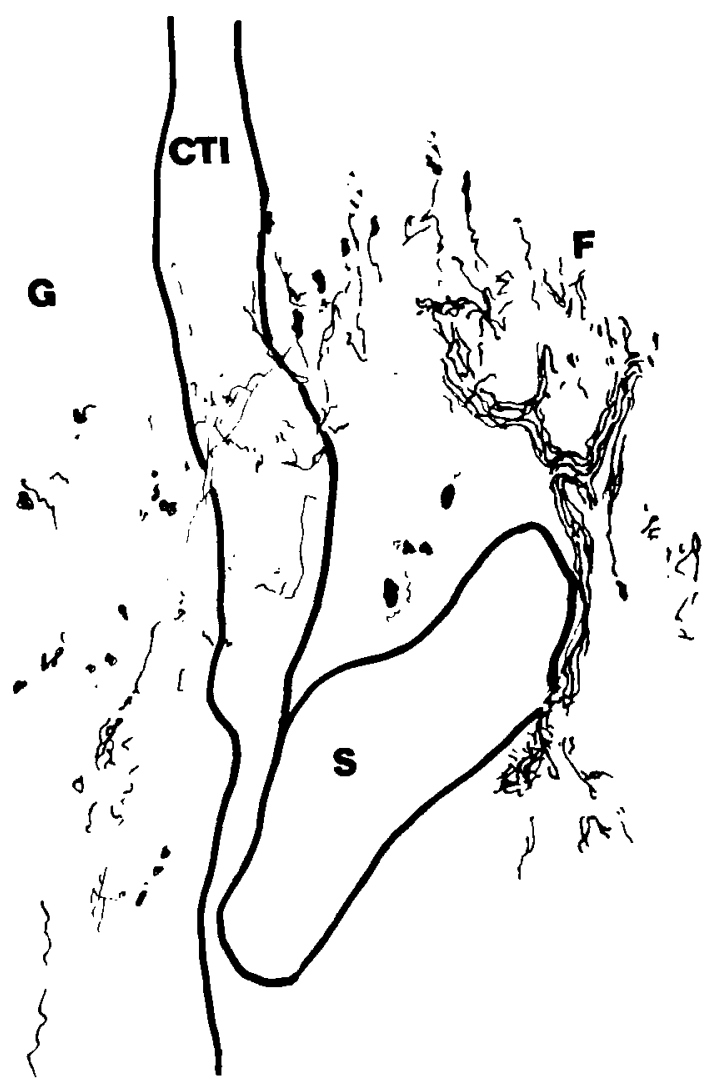

FIGURE 3. Reconstruction showing black nerve fibers crossing from the feeder muscle $(F)$ to the graft muscle $(G)$. CTI = connective tissue interface, $S=$ suture.
Soleus Controls. Solcus transplants were used to control for the possibility that reinnervation of the grafted strap muscles came from the cul strap muscle nerves. Histological examination of the soleus graft/feeder muscles of two animals killed at 35 days and 5 animals killed at 53 days showed that nerves from the sternohyoid feeder muscles had crossed into the soleus muscle grafts. No nerves were seen entering the soleus grafi from anywhere outside of the fecder muscle.

Experiment 2: MEP-less Grafts. The purpose of this experimental series was to examine the hypothesis that the motor endplate region of a free muscle graft is important for the muscular neurotization of that graft.

Procedure and Results. From the stcrmohyoid or sternomastoid muscles a distal portion of the muscle containing no motor endplates (MEP-less) was grafted to the standard position on the sternohyoid feeder muscle.

Of the 60 MEP-less grafts, 14 were stemohyoid and 46 were sternomastoid grafts. The results of both series were similar, so the two series of MIEPless grafts were pooled. There were 25 animals that had no nerves in their MEP-less grafts. However, in the remaining 35 animals nerves were present in the MEP-less grafts. Nerves in these grafts frequently terminated on small spots of esterase resembling motor endplates. These 35 animals, $58 \%$ of the total number of animals, do not support the hypothesis that the motor endplate region is essential for the muscular neurotization of a free muscle graft. The results of a chi-square test indicate that the MEP-less graft results do not differ significantly from those of the standard grafis $(P=0.21)$.

Experiment 3: "Sutureless" Grafts. Examination of standard and MEP-less grafts often showed a close association of the entering nerves with the sutures holding the free muscle graft to the feeder muscle. Figure 3 shows a suture near the area of nerve crossing. Figure 4 shows even more dramatically the association of nerves with sutures. The following experiment was designed to test the hypothesis that muscular neurotization would not occur without the presence of sutures.

Procedure and Results. In order to avoid tratuma to the sternohyoid feeder muscle, a very long sternomastoid free muscle graft was sutured rostrally into the tendinous region of the anterior cligastric muscle and caudally into the muscle covering the sternum. Some of the grafts were sutured caudally 


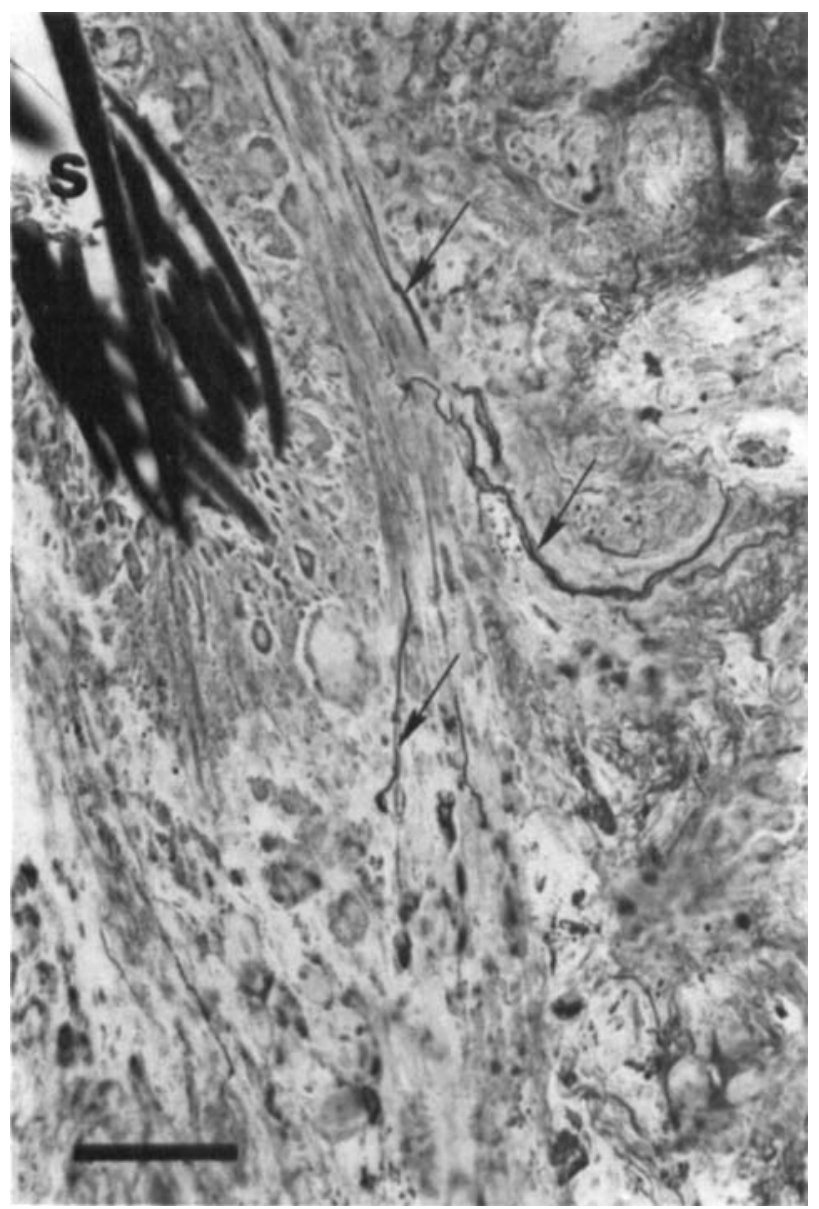

FIGURE 4. Nerves (arrows) in graft. These nerves originated from the feeder muscle and entered the graft along with the suture (S). Bar $=100 \mu \mathrm{m}$.

into the most caurdal region of the stemohyoid muscle.

The results from 31 "sutureless" gratts taken at time periods of $28,35,50$, and 60 days indicate that sutureless grafts were not reinnervated by nerves arising from an "undisturbed" adjaccent muscle (Fig. 5). Of the 31 grafts, 11 contained no nerves, whereas 20 had some nerves present. All of the nerves present could be traced through serial sections to the caudal or rostral ends of the "sutureless" grafis where they cntered accompanying either a suture or a blood vessel. These nerves did not arise from the sternohyoid feeder muscle. Isually the entering nerves were associated with estcrase spots located far from the original motor endplate region of the graft, but in some gratts nerves were also secn in the vicinity of the original motor endplate region.

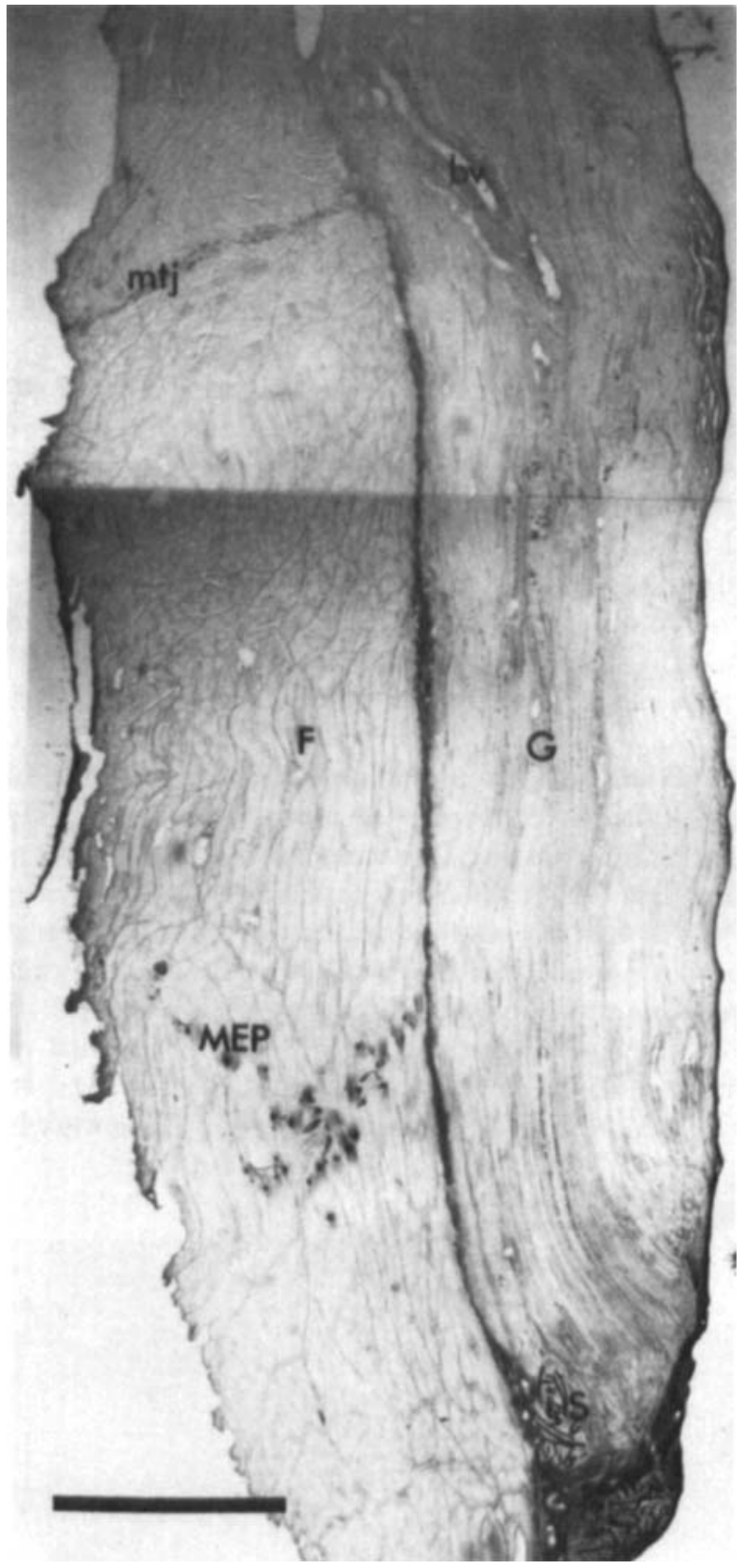

FIGURE 5. Overview of "sutureless graft" and feeder muscle. $\mathrm{F}=$ feeder, $\mathrm{G}=$ graft, $\mathrm{S}=$ suture, $\mathrm{MEP}=$ motor endplate region bv $=$ blood vessel, $\mathrm{mtj}=$ myotendinous junction. Bar $=10 \mu \mathrm{m}$.

\section{Experiment 4: Sutured Feeder with a Sutureless Graft.} The sutureless model showed that the placement of a free muscle graft on top of an intact muscle did not provide a sufficient stimulus to cause muscular neurotization. It was hypothesized that the presence of nerves in the standard and MEP-less grafts was due 10 nerve injury caused by the sutures 
in the feeder muscle. The injured nerves then regenerated and randomly grew throughout the feeder. Occasionally the sutures were used as a pathway by the regenerating nerves to cross into the graft.

This hypothesis has two parts: (1) damage to the feeder muscle is necessary for the nerve response seen in the standard and MEP-less grafts, (2) a pathway is necessary to permit the regenerating nerves to cross into the graft. By hypothesizing that the feeder nerves are damaged by crushing from the sutures, one assumes the nerve response is nerve regeneration rather than nerve sprouting.

Procedure and Results. In 9 animals 2 stitches (Ethicon 7-0) were tied tightly on the dorsal side of the sternohyoid muscle in the region of the nerves and motor endplates. The right sternomastoid muscle was then transplanted as a "sutureless graft" to the ventral surface of the left stemohyoid musde.

There was a massive regenerative response of the injured feeder muscle nerves, but no nerves were seen crossing the connective tissue interface between feeder and graft (at 35 days). Some grafts $(n=5)$ had nerves that originated from the caudal or rostral ends of the graft, but no nerves were seen coming from the damaged feeder muscle

The tight sutures had caused a great deal of damage to the feeder muscle and nerve fibers. In each feeder muscle there were regenerating muscle fibers, often in a disarraved pattern. Silver stains showed a massive production of small nerve fibers. The regenerating nerve fibers had several abnormal morphological characteristics. They were frequently less linear than normal nerves, i.e., they were zig-zagged (Fig. 6) and often had a beaded or blebbed appearance. In the damaged feeder muscles the nerves often ran parallel to the muscle fibers rather than in the normal perpendicular direction.

\section{Experiment 5: Scraped Feeder with a Sutureless Graft.} This experiment was designed to determine whether the regenerative response of the nerves wats due to a property of the suture material or to the acute mechanical damage caused by the sutures.

Procedure and Rerults. The ventral surface of the feeder muscle was scraped several times with at tool made of five straight pins taped together at their head ends. The right stemomastoid was then placed as a sutureless graft on the ventral surface of the sternohyoid feeder.

Alter 35 days 4 grafts showed no regenerated nerves, 7 had nerves that were traceable to nonfeeder muscle sources, and 1 had norves that rig. inated in the feeder.

Experiment 6: Scraped Feeder with a Scraped Sutureless Graft. Although the fascial coverings of the strap muscles are relatively thin, a possibility ex-

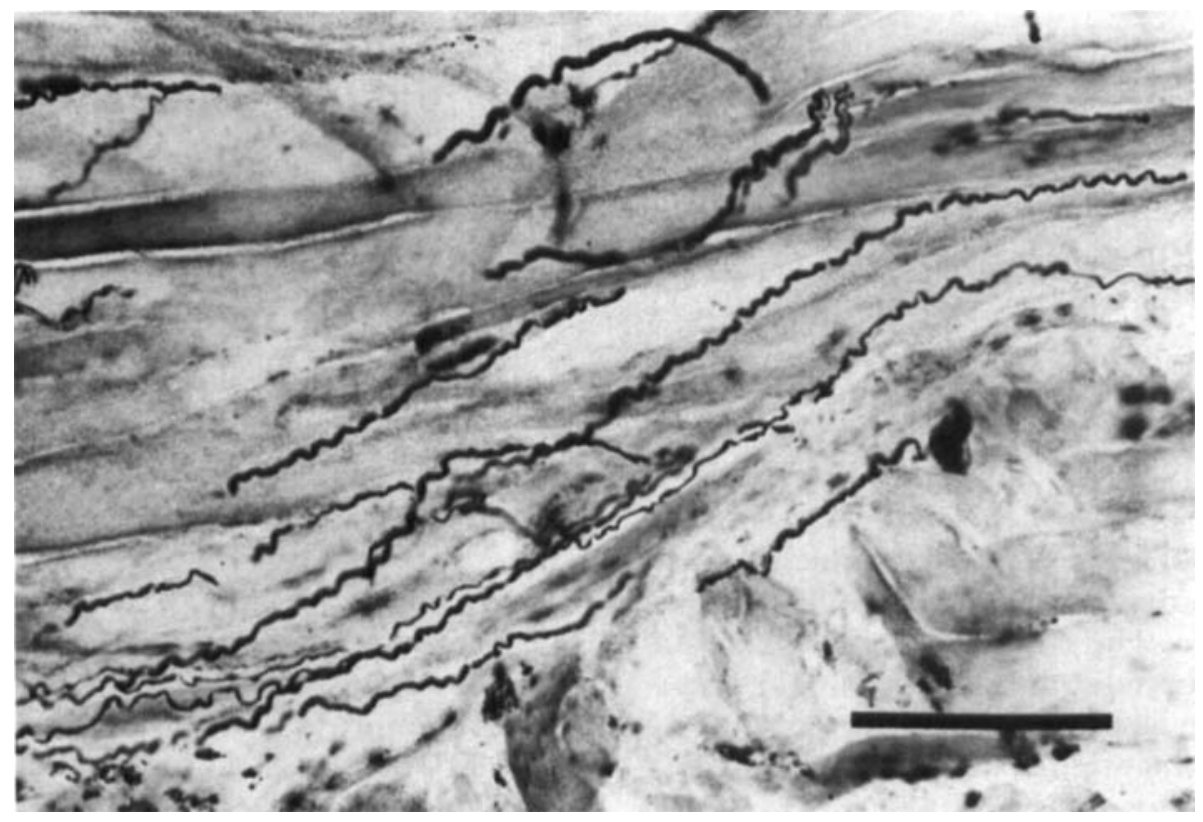

FIGURE 6. Regenerated nerves in a damaged feeder muscle. Note zig-zagged appearance and general parallel direction with the long axis of the muscle fibers. Bar $=100 \mu \mathrm{m}$. 
isted that the comnective tissue interface between the feeder and graft muscles was acting as a barrier to the regenerating nerves in the damaged feeder muscle. Scraping the feeder muscle disrupted the continuity of the fascia on the feeder side, but the graft still had its portion of the fascia intact. Scraping of the interposed fecder and graft surfaces should sufficiently disrupt or eliminate the connective tissue interface between the two muscles.

Procedure and Results. In this experiment 19 sutureless grafts of scraped sternomastoid muscles were transplanted to the scraped ventral surface of the left sternohyoid muscle.

Of these 19 animals. 6 had no nerves present in the grafts, and 6 had nerves traceable to nonfeeder sources. Three had nerves originating in the feceler muscle and four had nerves that may have been from the feeder muscle, but the nerve origin was not clear.

Scraped Sutureless Control. As a control a series of scraped sutureless sternomastoid grafts were placed on undamaged feeder muscles. Of the seven control grafts, one had no nerves present, whereas the remaining six had nerves originating from nonfeeder sources.

\section{DISCUSSION}

The first experiment in this series confirmed that it is possible to reinnervate free muscle grafts by nerves from adjacent muscles. The second experiment indicated that the motor endplate region could not be considered the main stimulus for nerve growth into the graft. 'The third experiment implied that if there was no damage to the nerves of the feeder muscle, the free muscle grafts do not become reinnervated. The final three experiments demonstrated that if the feeder muscle nerves are injured, and certain other requirements are met, it is possible for a nerve to reinnervate an adjacent free muscle graft without providing a direct pathway.

The nerve fibers that entered the standard grafts often were associated with the motor endplate regions of these grafts. Because of these results it was initially hypothesized that there may be a nerve sprouting stimulus associated with the motor endplate region. According to the working hypothesis, nerves were not expected to reinnervate the MEPless grafts permanently because there was no remaining original endplate region. ${ }^{1}$ However, the results of this experiment show that not only do nerves enter the MEP-less grafts, but according to the esterase stain, they also were able to establish new motor endplates. Clearly, the muscular neu- rotization of these grafts is not dependent on the presence of a preexistent motor endplate region.

The results from the sutureless experiment indicate that in grafts up to 60 days old, nerves from the feeder muscle do not simply sprout and cross into an adjacent free muscle graft. Damaging the feeder muscle nerves, by suturing or scraping before applying the graft, clearly showed that although there was a massive regenerative response of the damaged feeder nerves, these nerves were seen crossing from the feeder muscle to the graft in only a small number $(13 \%)$ of the grafts. The beaded appearance of these nerves was indicative of regenerating nerves in each of the different experimental procedures.

The regenerative response of the feeder nerves may have been due directly to nerve damage to the feeder nerves or it might have been a response to damage of the surrounding feeder muscle fibers. These experiments were not designed to separate these two factors. The experiments simply show (1) that the feeder nerves do respond to the suturing or scraping of the feeder muscle and (2) that these actively regenerating feeder nerves do not cross the connective tissue interface into the degenerating and regenerating free muscle graft.

The results of the experiment in which only the graft was scraped indicate that mechanical damage to the graft alone is not enough of a stimulus to cause or allow feeder nerves to cross into the graft. Only when both the surface of the feeder and the closely apposed surface of the graft were scraped and damaged did muscular neurotization occur; regenerating nerves from the feeder muscle crossed into the graft. In these cases, muscular neurotization occurred in the absence of any suture pathway.

In this work regenerating nerves often followed muscle fibers that seemed to span the feeder and the graft. The use of muscle fiber basal lamina as a nerve pathway has been noted by other investigators. ${ }^{10}$ Once in the graft the regenerating nerve fibers showed a marked preference for old nerve sheaths. In several animals the crossing nerve fibers were observed to empty into the remaining old nerve trunk sheath of the graft muscle. The nerves were then directed up the old sheath towards the motor endplate region.

\section{CONCLUSIONS}

Since the time of Erlacher ${ }^{4}$ it has been standard practice to "freshen" or vigorously scrape the surface of the muscle on which the graft is to be laid. Although the scraping was originally initiated to remove or destroy a portion of the connective tissue 
sheath surrounding the muscles in order to allow the nerves to enter the graft, it now seems that the scraping also damages those nerve fibers near the surface of the intact muscle. Damaging the intact nerves allows them to undergo a classic nerve regenerative response. These nerves are then capable of growing several millimeters to innervate an adjacent muscle transplant. This is in marked contrast to the nerve sprouting response, which elicits nerve growth of only several micrometers in length.

Regenerating nerves often followed sutures as a pathway into the graft. Frey et al.$^{6}$ mention that their grafts were closely applied to the adjacent intact muscle by many sutures around the edges of the grafts. From the results of this work one might suggest that it may be wise also to suture through the center of the graft and feeder muscle, especially in the region of the feeder muscle endplates. The sutures served not only as a pathway but also as a mechanism to crush or damage the feeder nerves. This suture-initiated injury causes a regenerative nerve sprouting response. The nerves wind their way along the sutures from inside the feeder, across the connective tissue interface, and into the graft.

In conclusion, muscular neurotization of the variety investigated here must be classified as a form of nerve regeneration in which nerves in one muscle regenerate to innervate an adjacent muscle transplant. This work indicates that the stimuli responsible for muscular neurotization are mechanical rather than chemical. The presence of sutures in the graft and feeder muscles provide (1) a source of injury to the feeder muscle nerves and (2) a pathway upon which the regenerating nerves may grow into the graft.

\section{REFERENCES}

1. Bader D: Reinnervation of motor endplate containing and motor endplateless muscle grafts. Dez Biol 77:315-327, 1980

2. Carlson BM. Gutmann E: Regeneration in free grafts of normal and denervated muscles in the rat: morphology and histochemistry. Anat Rec 183:47-61, 1975.

3. Carlson BM, Gutmann E: Regeneration in grafts of normal and denervated rat muscles: contractile properties. Pfuegers Arch 353:215-225, 1975.

4. Erlacher R: Direct and muscular neurotization of paralyzed muscles. Am J Orthoped Surg 13:22-32, 1915.

5. Freilinger G, Holle J. Mamoli B: Free muscle transplants for anal sphincter reconstruction in pigs. Chir Plast (Berl) 2: $133-141,1974$.

6. Frey M, Gruber H. Holle J, Freilinger G: An experimental comparison of the different kinds of muscle reinnervation: nerve suture, nerve implantation, and muscular neurotization. Plast Reconstr Surg 69:656-667, 1982.
7. Goshgarian HG: A rapid silver impregnation for central and peripheral nerve fibers in parafitin and frozen scctions. Exp Neurol 57:296-301, 1977.

8. Gruber H, Freilinger G, Holle J. Mayr R: Motor plates in autologous muscle transplants. Experientia 30:1191-1192, 1974.

9. Hakelius L: Free muscle grafting. Clin Plast Surg 6:301-316, 1979.

10. Huang $\mathrm{CH}$, Kevnes RJ: Terminal sprouting of mouse motor nerves when the post synaptic membrane degencrates. Brain Res 274:225-229, 1983.

11. Miller TA, Korn HN, Wheeler ES, Eldridge L: Can one muscle reinnervate another: A preliminary sudy of muscular neurotization in the rabbit. Plast Reconstr Surg 61: 50-57, 1978.

12. Thompson N: Autogenous free grafts of skeletal muscle Plast Reconstr Surg 48:11-27, 1971. 